\title{
Peptide-protein microarrays and surface plasmon resonance detection: biosensors for versatile biomolecular interaction analysis
}

\author{
Marie-Bernadette Villiers ${ }^{1,2^{*}}$, Sandra Cortès ${ }^{1,2^{*}}$, Carine Brakha ${ }^{1,2}$, Jean-Pierre \\ Lavergne $^{3}$, Christophe A. Marquette ${ }^{4}$, Paul Deny ${ }^{5}$, Thierry Livache ${ }^{6}$ and Patrice N. \\ Marche $^{1,2}$ \\ ${ }^{1}$ INSERM, U823, IAPC, 38041 Grenoble Cedex 9, France \\ ${ }^{2}$ Université J. Fourier, BP53, 38041 Grenoble Cedex 9, France \\ ${ }^{3}$ IBCP, UMR 5086 CNRS-Université de Lyon, IFR 128 Biosciences, 69367 Lyon cedex 7, \\ France \\ ${ }^{4}$ UMR 5246 CNRS-UCBL, ICBMS, 69622 Villeurbane Cedex, France \\ ${ }^{5}$ INSERM, U871, Hospices civils de Lyon, Université Lyon 1, 69424 Lyon Cedex 3, France \\ ${ }^{6}$ UMR SprAM 5819 (CEA, CNRS, UJF), INAC, 38054 Grenoble cedex 9, France \\ * These authors equally contributed to the work and should be considered as first authors \\ Corresponding author: Marie-Bernadette VILLIERS, INSERM, U823, équipe 8, Institut \\ Albert Bonniot, BP170, F-38042 GRENOBLE Cedex9, France. \\ Ph: + 334765494 33; Fax: + 33476549414 \\ E-mail: Marie-Bernadette.Villiers@ujf-grenoble.fr
}

\begin{abstract}
Biosensors in microarray format provide promising tools for high-throughput analyses of complex samples. Although they are able to detect, quantify and characterize a multitude of compounds, most of the available devices are specialized in the analysis of one type of interaction, limiting their application to a define area. The aim of our work was to develop and characterize versatile protein (or peptide) microarrays suitable for the simultaneous analysis of a large panel of biological interactions. Our system involved a simple procedure to immobilized proteins or peptides, based on pyrrole electropolymerization, and ligand binding was detected by imaging the surface plasmon resonance. We demonstrated its suitability in three different contexts, i.e. humoral response characterization, ion binding analysis and cell detection. This work evidences the potentiality of this approach which allows multiparametric, high throughput and label-free analysis of biological samples suitable for the detection of compounds as various as proteins, ions or cells and the characterization of their interaction with peptides or proteins.
\end{abstract}

Key words: Microarray; Surface Plasmon Resonance imaging; protein; peptide; cell; ion 


\section{Introduction}

Multiparametric analyses of various parameters in a rapid and high-throughput way represent a great challenge in many domains of application for biology. Since the advent of microarrays in the 90 s and their fruitful use in gene expression monitoring (Schena et al. 1995), many efforts were made to enlarge their use in other fields than genomic. Indeed, their characteristics allow high-throughput analysis of small samples within a short time together with low-cost assays (Howbrook et al. 2003). Nevertheless, whereas progress of DNA chips was rapid, leading to their wide use and commercialisation (Affymetrix), advance of other microarrays such as those based on protein immobilization was slower. The complexity and heterogeneity of proteins, along with the necessity to keep their folding and their spatial conformation intact after binding on the chip surface are certainly parameters which have hampered the use of proteins in microarrays. In some cases, peptide chips are a good alternative to protein arrays because the simplicity of the structure of such probes confers to them a great stability and makes them easier to produce.

Microarray technology involves two major steps, i.e. probes immobilization and detection of molecular interactions. These steps are often related and mostly depend on the question which is addressed. Therefore, different types of array are needed to implement the wide variety of biological assays. For example, probes can be directly synthesized on the support, but this methodology applies only to oligonucleotides (Phillips et al. 2008) or peptides (Gao et al. 2004). Protein attachment can be performed either by physical adsorption, or by affinity or covalent binding (for review, see Rusmini et al. 2007). The passive adsorption leads to highly variable binding efficiency depending on the molecule since the surface charge of proteins is variable and influences their interaction with the support (Angenendt et al. 2003). Moreover, regeneration of the chip surface using different solutions (acidic or basic $\mathrm{pH}$, high ionic strength) can lead to the desorption of the probes, preventing an efficient reuse of the chip. Affinity or covalent binding requires the presence of special groups/molecules on the surface such as nitrilotriacetic acid which can react with His-tag proteins via $\mathrm{Ni}^{2+}$ ions (Kang et al. 2007) or streptavidin to retain biotinylated probes (Pavlickova and Hug 2004).

Bifunctional molecules can also be used: one functional group allows the binding to the surface (via hydroxyl groups present on glass for example) and a second group the reaction with primary amine groups of proteins (MacBeath and Schreiber 2000). However, these methods usually imply multi-step procedure increasing time and cost for their realization and are not always suitable for high density probe immobilization. Moreover, the process used for biological molecule immobilization must be compatible with the ensuing detection. Various strategies have been developed, most of them involving secondary molecules such as antibodies and/or labels such as fluorescence dyes ( $\mathrm{Yu}$ et al.). Although these methods allow signal amplification and thus have a good sensitivity, their applications are thereby limited. Furthermore, they provide end-point measurements without access to kinetic parameters of the binding. Therefore, several works emphasize on direct detection technologies (for review, see Espina et al. 2004). Among them, surface plasmon resonance (SPR) is an optical method allowing the monitoring of biological interactions occurring at the surface of biosensors. Those consist in glass supports layered with a metal film (usually gold) to obtain surface plasmon. Advance of SPR imaging (SPRi) allows this method to be compatible with microarray format for multiparametric measurements. This approach, first described by Rothenhaüsler and Knoll (Rothenhäusler and Knoll 1988) and Jordan et al. (Jordan et al. 1997) for 
DNA chip, was successfully applied to peptides, proteins and oligosaccharides (Cherif et al. 2006; Kerdiles et al. 2006; Uzawa et al. 2008).

Taking into account that an optimal microarray would present advantages for the analysis of a large range of biomolecular interactions while being easy to realize via a single-step procedure, we develop a versatile biosensor using SPRi detection associated with a simple chemistry to immobilize probes (peptides or proteins) such as pyrrole electropolymerization (Livache et al. 1994). This chemistry allows rapid covalent immobilization of different kinds of molecules on spatially defined spots. Here, we demonstrate the potential of such a system offering direct detection of the binding of various types of ligands such as proteins, ions and cells.

\section{Experimental}

\subsection{Reagents}

Bovine serum albumin (BSA) and Hen Egg Lysosyme (HEL) were obtained from Sigma-Aldrich (St Quentin Fallavier, France) and Merck (Paris, France) respectively. A97, a polypeptide from hepatitis $\mathrm{C}$ virus (HCV) Alternate Reading Frame Protein (ARFP) (Bain et al. 2004) was provided by J.-P. Lavergne. $\mathrm{Ni}$ and $\mathrm{Co}$ binding sites in peptides were determined with SVM-prot software (http://jing.cz3.nus.edu.sg/cgibin/svmprot.cgi). Pyrrole-protein conjugates were generated as described (Kerdiles et al. 2006). Peptides (Table 1 of supplementary data) derived from Ovalbumin (Ova), $\mathrm{HCV}$ and hepatitis D virus (HDV) were synthesized with a pyrrole-modified $\mathrm{NH}_{2}$ terminus by Altergen, Bischheim, France. P12 from tetanus toxin and Poly H (6 His) was obtained from Altergen, Bischheim, France and pyrrole-poly $\mathrm{H}$ conjugates were generated as described in (Cherif et al. 2006). Monoclonal antibodies ( $\mathrm{mAb}$ ) against mouse MHC and CD90, and aspecific Ab used as control were purchased from BD Pharmingen (Le Pont de Claix, France). Mouse mAb against A97 (12F10) (Morice et al. 2009) was provided by J.-P. Lavergne. Human serums from healthy donors $(\mathrm{n}=2), \mathrm{HCV}$ infected patients $(\mathrm{n}=4)$ and HDV-infected patients $(n=3)$ were obtained from the Etablissement Français du Sang (La Tronche, France) and the Centre HospitaloUniversitaire (Hepatology and Virology services, La Tronche, France). Serums were stored at $-20{ }^{\circ} \mathrm{C}$.

\subsection{Materials}

Glass prisms on which a $50 \mathrm{~nm}$ gold layer was deposited were obtained from GenOptics-HORIBA Scientific (Chilly Mazarin, France). Electrodeposition was performed using an Omnigrid Micro robotic arrayer (GenOptics-HORIBA Scientific, Chilly Mazarin, France). SPR signals were monitored using a Surface Plasmon

Resonance imager from GenOptics-HORIBA Scientific (Chilly Mazarin, France): for antibody binding analyses, we used a SPRiPlex apparatus with a $6 \mu \mathrm{L}$ Teflon chamber and for cell or ion binding analyses, we used a SPRi-Lab with a $14 \mu \mathrm{L}$ Peek chamber, connected to a Waters 600E pump (Millipore, Lyon, France).

\subsection{Cell lines}

The murine B lymphocyte cell line LS102.9 (ATCC HB-97) was purchased at the American Type Culture Collection (Rockville, MD, USA). The murine T lymphocyte cell line 3A9 was kindly provided by $\mathrm{C}$. Rabourdin-Combe (INSERM, Lyon, France) (Allen et al. 1985). Both cell lines were grown in Dulbecco's modified eagle medium (Gibco, France) supplemented with $10 \%$ fetal calf serum (FCS), $0.1 \mathrm{mM}$ non essential amino acids, 1 $\mathrm{mM}$ sodium pyruvate, $50 \mu \mathrm{M} 2$ mercaptoethanol, $50 \mathrm{U} / \mathrm{mL}$ penicillin and 50 $\mu \mathrm{g} / \mathrm{mL}$ streptomycin. The human promyelocytic cell line U937 from the American Type Culture Collection 
(Rockville, MD, USA) (ATCC CRL1593.2) was grown in RPMI 1640 supplemented with $10 \% \mathrm{FCS}, 50 \mathrm{U} / \mathrm{mL}$ penicillin and $50 \mu \mathrm{g} / \mathrm{mL}$ streptomycin. All cultures were incubated at $37^{\circ} \mathrm{C}$ in a humidified $5 \% \mathrm{CO}_{2}$ incubator. Before injection of cells onto the chip, $\mathrm{Fc}$ receptors were blocked by pre-incubating the cells for $15 \mathrm{~min}$ in $15 \%$ human serum.

Table 1: Dissociation analysis: slope of the dissociation curves obtained after injection of serums from two HCV infected patients ( $\mathrm{SH}$ (2) and $\mathrm{SH}$ (3)) on a chip grafted with different HCV peptides (C2, E2/3, NS5/2, NS4/7).

\begin{tabular}{ccc}
\hline $\begin{array}{c}\text { Grafted } \\
\text { peptides }\end{array}$ & $\begin{array}{c}\mathrm{SH}(2) \\
10^{2} \mathrm{~min}^{-1}\end{array}$ & $\begin{array}{c}\mathrm{SH}(3) \\
10^{2} \mathrm{~min}^{-1}\end{array}$ \\
\hline $\mathrm{C} 2$ & $-3.09+/-0.37$ & $-2.72+/-0.58$ \\
$\mathrm{E} 2 / 3$ & $-0.03+/-0.13$ & $-0.00+/-0.00$ \\
$\mathrm{NS} 5 / 2$ & $-1.00+/-0.01$ & $-4.92+/-0.22$ \\
$\mathrm{NS} 4 / 7$ & $-4.48+/-0.24$ & $-4.62+/-0.25$ \\
\hline
\end{tabular}

\subsection{Protein and peptide immobilization on gold}

Probes were immobilized on the gold surface of the chip $\left(80 \mathrm{spots} / \mathrm{cm}^{2}\right)$ by electrochemical copolymerization of pyrrole with $50 \mu \mathrm{M}$ (A97 or HEL) or $2 \mu \mathrm{M}$ (mAb) pyrrole-proteins conjugates or $100 \mu \mathrm{M}$ pyrrole-modified peptides according to Cherif et al. 2006. A negative control (Ppy), consisting in electropolymerization of pyrrole alone was realised. Each probe was deposited in triplicate $(500 \mu \mathrm{m}$ diameter spots); then, the gold chip was rinsed with distilled water and saturated at room temperature for $30 \mathrm{~min}$. Saturation solution was either $2 \%(\mathrm{w} / \mathrm{v}) \mathrm{BSA}$ in phosphatebuffered saline $\left(\mathrm{PBS}=1.5 \mathrm{mM} \mathrm{KH}_{2} \mathrm{PO}_{4}, 8.1\right.$ $\mathrm{mM} \mathrm{Na}_{2} \mathrm{HPO}_{4}, 2.7 \mathrm{mM} \mathrm{KCl}, 138 \mathrm{mM} \mathrm{NaCl}$, $\mathrm{pH}$ 7.1) for $\mathrm{Ab}$ and ion binding analyses or poly(L-Lysine)-PEG (SurfaceSolutionS, Zurich, Switzerland) $1 \mathrm{mg} / \mathrm{mL}$ in PBS for cell binding analyses. After saturation, the chip was washed with distilled water and placed in the SPRi apparatus.

\subsection{SPRi interaction monitoring}

All reactions were carried out at room temperature, in PBS alone or supplemented with $0.5 \%$ BSA (w/v) and/or $0.005 \%(\mathrm{w} / \mathrm{v})$ Tween 20 as indicated in the text. The flow rate in the chamber was $37 \mu \mathrm{L} / \mathrm{min}$ (SPRiPlex) or $100 \mu \mathrm{L} / \mathrm{min}$ (SPRi-Lab). Ligands (ions, $\mathrm{Ab}$ or cells) were injected in a volume of $500 \mu \mathrm{L}$ and the biochip surface was rinsed to remove unbound ligands. After ion or $\mathrm{Ab}$ binding, the chip was regenerated by $0.2 \mathrm{M}$ imidazole or $0.1 \mathrm{M} \mathrm{HCl-Glycine} \mathrm{(pH} \mathrm{2.3)}$ respectively for $5 \mathrm{~min}$. SPR imaging was used to monitor ligand binding, as detailed in Cherif et al. 2006. Measurements were performed using SPRi dedicated software (GenOptics-HORIBA Scientific, Chilly Mazarin, France).

\section{Results and discussion}

\subsection{Qualitative and quantitative analysis of $A b$ in patient serums}

Analysis of humoral response upon infection and/or after treatment is a challenge for diagnosis and prognosis and, most generally, to understand the immune response mechanisms against pathogens. Whereas most of the antigen arrays designed for antibody profiling are based on indirect method requiring additional labeled partner (Bannantine et al. 2008; Li et al. 2008), SPRi is an optical method presenting the advantage of allowing direct molecular interaction measurements without labelling. We first evaluated the efficiency of this method for the characterization and quantification of specific $\mathrm{Ab}$ in a microarray format. To this end, a polypeptide from $\mathrm{HCV}$ protein ARFP (A97) was immobilized on a gold chip using polypyrrole electropolymerization process ( $\mathrm{cf} \$ 2.4)$ and the specific $\mathrm{mAb}(12 \mathrm{~F} 10)$ raised against this 
protein was injected. As shown in Fig.1a, injection of $12 \mathrm{~F} 10$ induced an increase in the reflectivity signal on spots bearing A97, whereas a very low signal was obtained on the controls consisting in spots grafted with an irrelevant protein (HEL) or with no probe (Ppy). This change of reflectivity was measured and yielded to a typical binding curve (sensorgram, Fig.1b): following an initial increase induced by ligand binding (association), a decrease of the reflectivity signal was observed upon washing (dissociation).

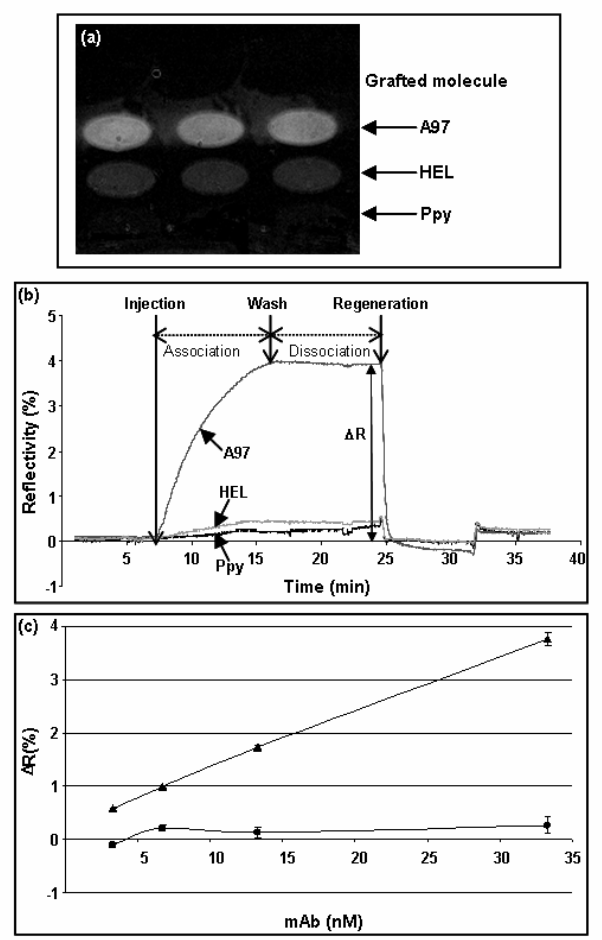

Fig. 1. Analysis of $\mathrm{Ab}$ binding to peptide chip by SPRi: (a) SPR differential image of the chip after injection of $12 \mathrm{~F} 10 \mathrm{mAb}$ (33.3nM) on a peptide chip which was grafted with peptide A97. Spots with HEL and Ppy alone serve as negative controls. (b) Corresponding sensorgrams obtained on A97, HEL and Ppy alone spots. (c) Correlation between SPRi signal $(\Delta \mathrm{R})$ on A97 ( $\Delta)$ and HEL $(\bullet)$ spots and the amount of injected $12 \mathrm{~F} 10 \mathrm{mAb}$ after subtraction of the background signal (Ppy spots).

The dissociation curve corresponds to the fast removal of non-specific binding if any followed by the dissociation of the surface bound-complexes. Thus, Ab binding led to a specific signal corresponding to the difference between the SPRi signal $(\Delta \mathrm{R})$ obtained on the positive assay and the controls. A regeneration step, consisting in the injection of HCl-Glycine $\mathrm{pH}$ 2.3, eliminated bound $\mathrm{mAb}$ to return to the initial signal level, thus allowing successive injections and measurements.

Then we evaluated if the SPRi signal correlated with the amount of injected mAb. Different concentrations of $12 \mathrm{~F} 10 \mathrm{mAb}$ were successively injected on the chip whose surface being regenerated after each assay. As shown in Fig.1c, dose-dependent signals were obtained on the A97 spot, whereas the signal on the control spots remained at a background level. In our conditions, we could detect $\mathrm{mAb}$ binding from a solution with a concentration of the order of the nanomolar which is the typical limit of detection of non amplified SPR-based assays (Scarano et al. 2009).

One important application of this method is the analysis of complex $\mathrm{Ab}$ mixture present in serum for instance from patients suffering from infection diseases. Determination of the serological specificity requires the analysis of numerous potential antigens that would benefit from the microarray format of our system. Indeed, a large number of potential antigens or epitopes can be immobilized on the chip ( 80 spots) and tested for their reactivity against Ab. Viral hepatitis is an interesting model since $\mathrm{Ab}$ specificities are thought to define a signature of the outcome of infection, i.e. chronocity, cirrhosis, hepatocarcinoma or recovery and of the response to treatment (Frangeul et al. 1998; Koshy and Inchauspe 1996). We designed a chip grafted with peptides ( 20aa) bearing potential epitopes of various regions of the $\mathrm{HCV}$ proteins to determine by SPRi detection $\mathrm{Ab}$ profiles from serums of infected patients. Five $\mathrm{HCV}$ peptides were grafted in triplicate on a chip together with a control irrelevant peptide (Ova) and serums from healthy $(\mathrm{n}=2)$ or HCV mono-infected patients $(n=4)$ were 

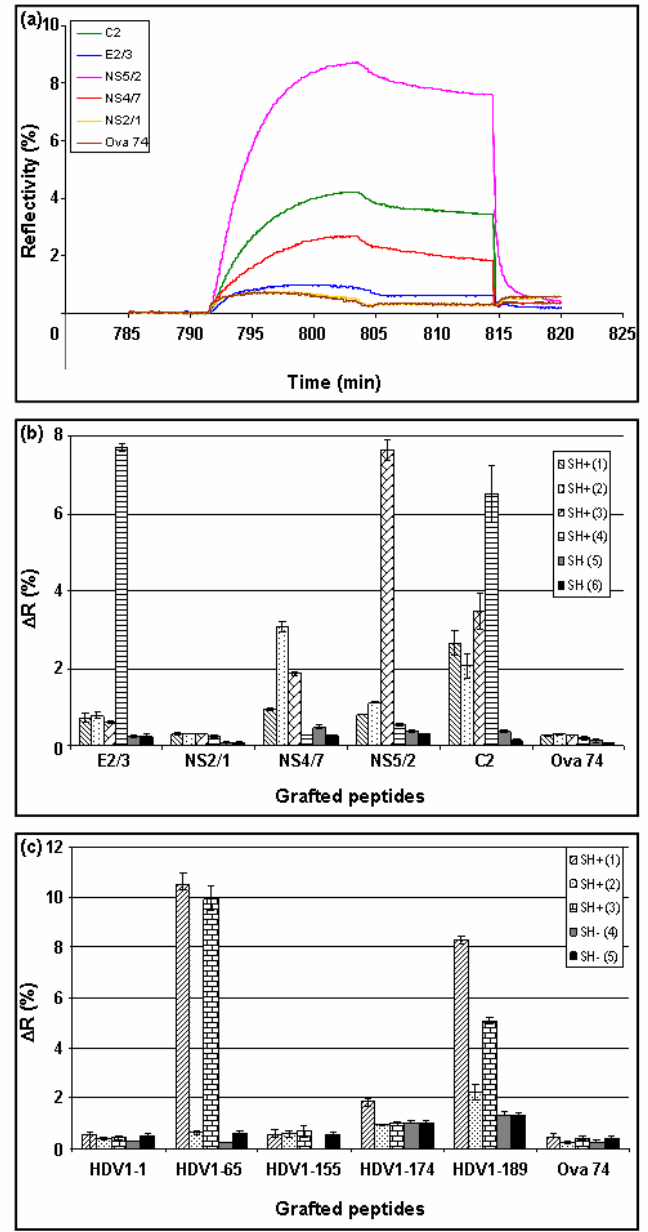

Fig. 2. Analysis of humoral response by SPRi: (a) Sensorgrams obtained when a serum from $\mathrm{HCV}$ infected patient was injected on a chip which was grafted with different HCV peptides and one irrelevant peptide as negative control (Ova 74). (b) SPRi signal $(\Delta R)$ obtained after injection of 4 serums from $\mathrm{HCV}$ infected patients $(\mathrm{SH}+)$ and 2 from non infected donors ( $\mathrm{SH}-)$ on a chip which was grafted with different HCV peptides and with a control peptide (Ova 74). (c) SPRi signal obtained after injection of 3 serums from $\mathrm{HDV}$ infected patients $(\mathrm{SH}+)$ and 2 from non infected donors ( $\mathrm{SH}-$ ) on a chip which was grafted with different HDV peptides and with a control peptide (Ova 74). ). This experiment is representative of three independent assays. Results are expressed as mean value $+/$ - standard deviations obtained from spots in triplicate.

analyzed. The serum samples were diluted $(1 / 50)$ in PBS, $0.005 \%(\mathrm{w} / \mathrm{v})$ Tween 20 and successively injected with a regeneration step between each sample. The reflectivity changes measured on each spot were recorded simultaneously (Fig.2a) and $\Delta \mathrm{R}$ values were determined from the sensorgrams (Fig.2b). The specific signal varied according to the tested serums and peptides, indicating differences, in terms of specificity and amount, in the anti-HCV Ab response of the patients. It is important to note that similar results were obtained in the context of another hepatitis virus infection (HDV, Fig.2c), strengthening the fact that our system is suitable to establish $\mathrm{Ab}$ profiles, showing that humoral responses are patient-related.

Ab specificity and amount are not the only characteristics of a humoral response. The interaction parameters, especially the dissociation rate constant (koff), are indicative for the efficiency of Ab binding. As SPRi detection allows label-free and realtime measurements, it gives access to these values. In the case of $\mathrm{Ab}$ present in serum, some precautions have to be taken: $\mathrm{Ab}$ elicited by a pathogen can display various degree of complexity in term of number of specificities. Therefore, the signal obtained upon $\mathrm{Ab}$ binding on a grafted peptide was the resultant of the interactions of different $\mathrm{Ab}$. In this case, it is difficult to determine a real koff value. Nevertheless, the slope of the sensorgram in the dissociation phase (upon washing) corresponds to the overall dissociation rate. This makes possible comparisons between the different serums. Thus, as shown in Table I, the dissociation rate depends both on the peptides and the patient serum.

Our system allows a rapid, label-free characterization of the humoral response through the analysis of the specificity, amount and dissociation rate of the $\mathrm{Ab}$ present in serums. This is of great interest for diagnosis and prognosis of a wide variety of diseases and could be enlarged to screenings of various protein- peptide or protein-protein interactions such as ligand-receptor, enzymesubstrate or protein-cofactor interplays. 


\subsection{Ion binding detection by SPRi}

Metal ions constitute basic elements in many biological systems and is involved in a large panel of mechanisms, from enzymatic activity to toxicity via oxidative mechanisms (Nagase 2001; Beyersmann and Hartwig 2008). Identification of proteins and/or sequences which interact with metal ions as well as detection of these elements in fluids are important for fundamental research in biology or environmental analysis. The versatility of our system prompted us to test its suitability for the detection of metal ion binding. Three peptides were chosen as probes, one consisting in a poly- $\mathrm{H}$ sequence known to interact with ions such as $\mathrm{Ni}^{2+}$ (Paborsky et al. 1996), another from tetanus toxin (P12), which includes two His and was described as interacting slightly with $\mathrm{Ni}^{2+}$ (Villiers et al. 1993) and the last one corresponding to an $\mathrm{HCV}$ sequence (NS4/7) devoid of Ni binding site. These peptides were grafted on a gold chip using polypyrrole electropolymerization process (cf §2.4) and different concentrations of $\mathrm{NiSO}_{4}$ were injected. Regeneration between each injection was performed using $0.2 \mathrm{M}$ imidazole. As shown in Fig.3a, a specific signal was observed on the poly-H spot whereas only weak signal was detected on the control spots (NS4/7 peptide and Ppy alone). The decrease in the number of His residues in the tested peptide (P12) strongly reduced $\mathrm{Ni}^{2+}$ binding. The specificity of the system was also assessed by injecting $\mathrm{CoCl}_{2}$ : as expected, no specific binding was observed on the tested peptides. Moreover, a very good correlation was obtained between the SPRi signal and the concentration of the injected $\mathrm{Ni}^{2+}$ (Fig.3b). It is usually assumed that SPRi signal results from a change in the refractive index near the gold surface caused by an increase in mass at the metal surface (Williams and Addona 2000). If it is the case for the binding of large ligands such as proteins or cells, another phenomenon is probably involved in the case of ion binding since the global increase in the mass is very

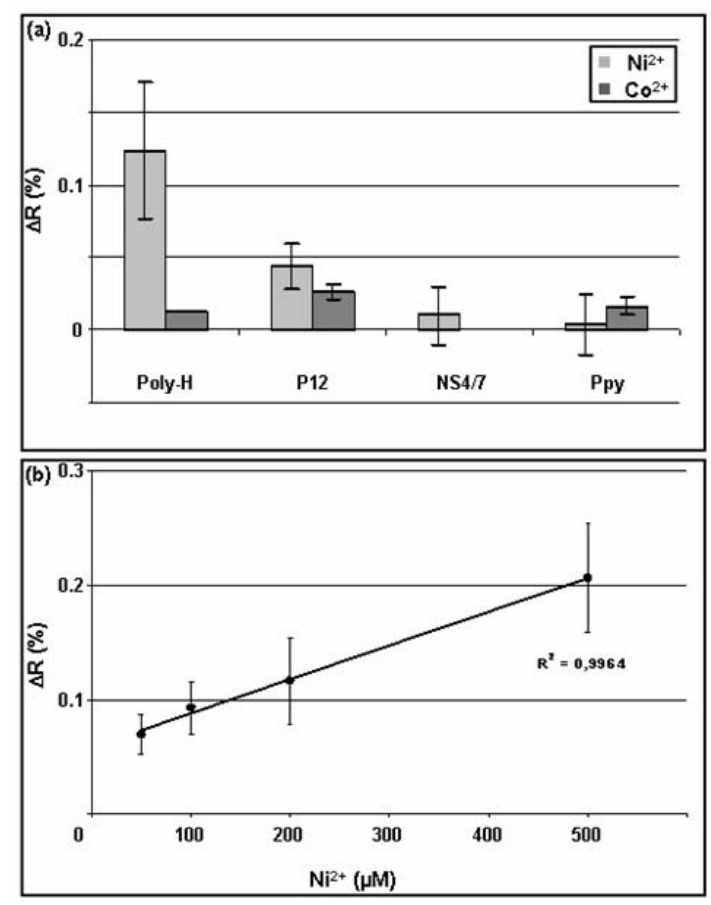

Fig. 3. Analysis of ion binding to peptide chip by SPRi: (a) SPRi signal obtained after injection of different concentrations of $\mathrm{Ni}^{2+}$ on a chip bearing poly-His, NS4/7 peptide and Ppy alone. (b) Correlation between specific SPRi signal $(\Delta \mathrm{R})$ on poly-His spots and the amount of injected $\mathrm{Ni}^{2+}$ after subtraction of the background signal (Ppy spots). This experiment is representative of three independent assays. Results are expressed as mean value $+/$ - standard deviations obtained from spots in triplicate.

weak. Moreover, an influence of the metal ion "per se" is unlikely as the refractive index of the metal solution, within the concentration range tested, was similar to that of the running buffer. It seems likely that

SPR signal is generated by a conformational change of the peptide induced by ion binding which modifies the structure of the peptide inducing a change in the mass gradient on the gold surface. Indeed, protein/peptide structure is known to change upon the binding of ligands, especially metal ions (Ivanova et al. 2008; Tougu et al. 2008). Nevertheless, the conformational change of the peptide may be not sufficient to account for the increase in 
SPR signal. Our data and previous ones (Palumbo et al. 2005; Palumbo et al. 2003) suggest an interference of the metal ion with the resonance phenomenon leading to an increase in the SPR signal. Although SPR has already been used for metal ion detection, our system differs from previously described ones (Forzani et al. 2005; Zhang et al. 2007), in associating SPR imaging to immobilization of the peptides in multiple spatially defined positions that supports multiparametric measurements. Thus, immobilization of different peptides, selected for their specific interaction with different metal ions, would allow high throughput analyses of peptide-metal ion interactions or metal ion content of a fluid.

\subsection{Biosensor-based cell capture and SPRi detection}

The different characteristics of our system (ease of manufacture of peptide/protein chips, high throughput, labelfree, real-time detection) prompted us to adapt the method for the specific capture and detection of discrete cells. The detection of sparse cells in biological samples is a frequent need in both biological and medical research. Samples issued from clinics are generally either blood cells or tissues from biopsies or surgery, where cells of interest are mixed with other cells of the donors. Although methods exist to identify discrete cells in complex samples, they require usually relatively large amounts of cells. Microsystems offer the possibility to analyze samples of a reduced size and therefore could contribute to the establishment of less invasive samplings. Several methods are currently used, based on nucleic acid sequence detection or on cell labeling and often require enrichment (Blumke et al. 2005; Pantel and von Knebel Doeberitz 2000). In order to develop a sensitive and discriminative method to directly detect cells in a mixed population, we immobilized on the chip surface $\mathrm{Ab}$ directed against cell surface markers. The cells injected on the chip were mouse T lymphocytes (3A9 cell line) together with mock cells consisting in U937, a human promyelocytic line. Different $3 \mathrm{~A} 9 / \mathrm{U} 937$ ratios (from $0 \%$ to $80 \%$ ) were injected with a total cell number equal to 300,000 cells. The different injections were realized successively, without chip regeneration which is unachievable probably owing to multiple-point binding between cells and $\mathrm{Ab}$. Thus, the measurements after each injection correspond to cumulated signal. Anti-CD90 $\mathrm{mAb}$ was used as $\mathrm{T}$ lymphocyte-specific $\mathrm{Ab}$ and we used a non specific IgG as negative control. As shown in Fig.4a, cell binding to immobilized $\mathrm{mAb}$ induced changes in the reflectivity: the signal increased with the number of injected $\mathrm{T}$ lymphocytes and was highly specific, since only a weak signal was obtained on the control spot and when U937 cells were injected alone. The specificity of the system was also assessed by injecting another cell type (B lymphocyte cell line LS102.9) on a chip bearing anti-CD90 mAb (T lymphocyte specific) and a $\mathrm{mAb}$ against a molecule present on B but not on T lymphocytes (antiMHC). Results were compared to those obtained upon T lymphocyte injection. As shown in Fig.4b, whereas T cells bound only on anti-CD90 spots, B cells interact only with anti-MHC spot. In both cases, only a weak signal was observed on the control spot (unspecific IgG). These results confirmed the high specificity of the cell-Ab interactions detected by this system.

\section{Conclusion}

The combination of a chip bearing peptides or proteins immobilized in a microarray format with SPR imaging provides a unique system which allows the detection of a large panel of ligands such as ions, proteins and cells. This method presents several advantages for label-free, multiparametric and real time analysis. The challenge consists in the design of probes allowing, by itself or in combination, discrimination between different ligands. The possibility of reducing the spot size to 5 $10 \mu \mathrm{m}$ diameter (Roupioz et al. 2009) allows 
the design of high-density microarrays for high-throughput analysis.
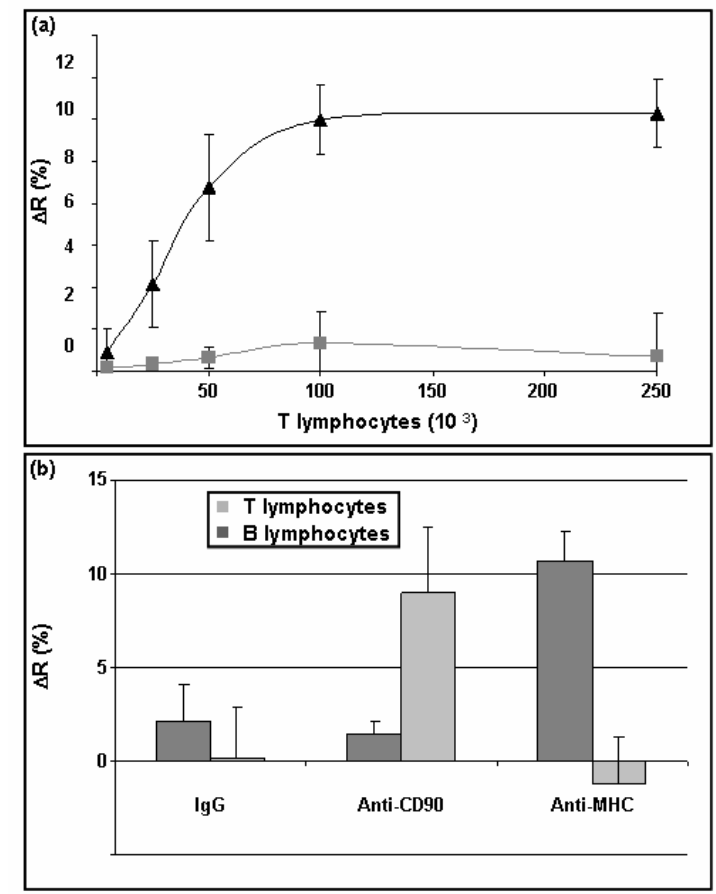

Fig. 4. Analysis of cell binding to Ab chip by SPRi: (a) SPRi signal $(\Delta \mathrm{R})$ obtained after successive injections of $T$ lymphocytes (3A9) mixed with U937 in different ratios $\left(3 \times 10^{5}\right.$ total cells) on a chip bearing $\mathrm{mAb}$ anti-CD90 ( $\mathbf{\Delta})$ and IgG control ( $\square$ ). (b) SPRi signal $(\Delta \mathrm{R})$ obtained on spots bearing $\mathrm{mAb}$ anti-CD90, anti-MHC and IgG control upon one injection of $5 \times 10^{5}$ cells (B or T lymphocytes) after subtraction of the background signal. Each experiment is representative of three independent assays. Results are expressed as mean value +/standard deviations obtained from spots in triplicate

Furthermore, precise localisation of the spots offers the possibility to obtain complex designs of the surface suitable for the quantification of several entities of different nature (ions, proteins, cells) in a single format. The same type of fluidic system can be used in all cases as the Peek chamber described for cell and ion detection is suitable for proteins (data not shown) although requiring a larger sample volume. Whatever the type of ligand tested, the sensitivity of our method is similar to what it is usually obtained with label-free biosensors (10 $0^{-9} \mathrm{M}$ for $\mathrm{Ab}$ (Labib et al. 2009), $10^{-5} \mathrm{M}$ for ions (Palumbo et al. 2005), $10^{4} / \mathrm{mL}$ for cells (Ishikawa et al. 2009).

The versatility of this system makes this technology a powerful tool which could be integrated in several domains such as clinical applications for the detection of biological markers, for basic research to study biological mechanisms and for environmental monitoring.

\section{Acknowledgements}

We thank Dr J.-P. Zarski and Pr P. Morand (Centre Hospitalo-Universitaire, La Tronche, France) for providing serums from patients. This work was supported by the Agence Nationale de Recherche sur le Sida (ANRS) and by the Fonds Unique Interministériel (FUI) "Biotherapic" and "Alpha Vac".

\section{References}

Allen, P.M., Matsueda, G.R., Haber, E., Unanue, E.R., 1985. J Immunol 135(1), 368-373.

Angenendt, P., Glokler, J., Sobek, J., Lehrach, H., Cahill, D.J., 2003. J Chromatogr A 1009(12), 97-104.

Bain, C., Parroche, P., Lavergne, J.P., Duverger, B., Vieux, C., Dubois, V., Komurian-Pradel, F., Trepo, C., Gebuhrer, L., Paranhos-Baccala, G., Penin, F., Inchauspe, G., 2004. J Virol 78(19), 10460-10469.

Bannantine, J.P., Paustian, M.L., Waters, W.R., Stabel, J.R., Palmer, M.V., Li, L., Kapur, V., 2008. Infect Immun 76(2), 739-749.

Beyersmann, D., Hartwig, A., 2008. Arch Toxicol 82(8), 493-512.

Blumke, K., Bilkenroth, U., Schmidt, U., Melchior, A., Fussel, S., Bartel, F., Heynemann, H., Fornara, P., Taubert, H., Wirth, M.P., Meye, A., 2005. Oncol Rep 14(4), 895-899.

Cherif, B., Roget, A., Villiers, C.L., Calemczuk, R., Leroy, V., Marche, P.N., Livache, T., Villiers, M.B., 2006. Clin Chem 52(2), 255262.

Espina, V., Woodhouse, E.C., Wulfkuhle, J., Asmussen, H.D., Petricoin, E.F., 3rd, Liotta, 
L.A., 2004. J Immunol Methods 290(1-2), 121133.

Forzani, E.S., Zhang, H., Chen, W., Tao, N., 2005. Environ Sci Technol 39(5), 1257-1262.

Frangeul, L., Cresta, P., Perrin, M., Duverlie, G., Khorsi, H., Musset, L., Opolon, P., Huraux, J.M., Lunel, F., 1998. J Hepatol 28(4), 538543.

Gao, X., Pellois, J.P., Na, Y., Kim, Y., Gulari, E., Zhou, X., 2004. Mol Divers 8(3), 177-187.

Howbrook, D.N., van der Valk, A.M., O'Shaughnessy, M.C., Sarker, D.K., Baker, S.C., Lloyd, A.W., 2003. Drug Discov Today 8(14), 642-651.

Ishikawa, F.N., Stauffer, B., Caron, D.A., Zhou, C., 2009. Biosens Bioelectron 24(10), 29672972.

Ivanova, E., Ball, M., Lu, H., 2008. Proteins 71(1), 467-475.

Jordan, C.E., Frutos, A.G., Thiel, A.J., Corn, R.M., 1997. 69(24), 4939-4947.

Kang, E., Park, J.W., McClellan, S.J., Kim, J.M., Holland, D.P., Lee, G.U., Franses, E.I., Park, K., Thompson, D.H., 2007. Langmuir 23(11), 6281-6288.

Kerdiles, Y.M., Cherif, B., Marie, J.C., Tremillon, N., Blanquier, B., Libeau, G., Diallo, A., Wild, T.F., Villiers, M.B., Horvat, B., 2006. Viral Immunol 19(2), 324-334.

Koshy, R., Inchauspe, G., 1996. Trends Biotechnol 14(10), 364-369.

Labib, M., Hedstrom, M., Amin, M., Mattiasson, B., 2009. Biotechnol Bioeng 104(2), 312-320.

Li, B., Zhou, D., Wang, Z., Song, Z., Wang, H., Li, M., Dong, X., Wu, M., Guo, Z., Yang, R., 2008. Microbes Infect 10(1), 45-51.

Livache, T., Roget, A., Dejean, E., Barthet, C., Bidan, G., Teoule, R., 1994. Nucleic Acids Res 22(15), 2915-2921.

MacBeath, G., Schreiber, S.L., 2000. Science 289(5485), 1760-1763.

Morice, Y., Ratinier, M., Miladi, A., Chevaliez, S., Germanidis, G., Wedemeyer, H., Laperche, S., Lavergne, J.P., Pawlotsky, J.M., 2009. Hepatology 49(5), 1449-1459.
Nagase, H., 2001. Curr Protoc Protein Sci Chapter 21, Unit 2124.

Paborsky, L.R., Dunn, K.E., Gibbs, C.S., Dougherty, J.P., 1996. Anal Biochem 234(1), 60-65.

Palumbo, M., Nagel, J., Petty, M.C., 2005. IEEE Sens. J. 5(6), 1159-1164.

Palumbo, M., Pearson, C., Nagel, J., Petty, M.C., 2003. Sens Actuators B Chem 91, 291-297.

Pantel, K., von Knebel Doeberitz, M., 2000. Curr Opin Oncol 12(1), 95-101.

Pavlickova, P., Hug, H., 2004. Methods Mol Biol 264, 73-83.

Phillips, M.F., Lockett, M.R., Rodesch, M.J., Shortreed, M.R., Cerrina, F., Smith, L.M., 2008. Nucleic Acids Res 36(1), e7.

Rothenhäusler, B., Knoll, W., 1988. Nature 332, 615-617.

Roupioz, Y., Berthet-Duroure, N., Leichle, T., Pourciel, J.B., Mailley, P., Cortes, S., Villiers, M.B., Marche, P.N., Livache, T., Nicu, L., 2009. Small 5(13), 1493-1497.

Rusmini, F., Zhong, Z., Feijen, J., 2007. Biomacromolecules 8(6), 1775-1789.

Scarano, S., Mascini, M., Turner, A.P., Minunni, M., 2009. Biosens Bioelectron 25(5), 957-966.

Schena, M., Shalon, D., Davis, R.W., Brown, P.O., 1995. Science 270(5235), 467-470.

Tougu, V., Karafin, A., Palumaa, P., 2008. J Neurochem 104(5), 1249-1259.

Uzawa, H., Ohga, K., Shinozaki, Y., Ohsawa, I., Nagatsuka, T., Seto, Y., Nishida, Y., 2008. Biosens Bioelectron 24(4), 929-933.

Villiers, M.B., Gabert, F.M., Jacquier, M.R., Villiers, C.L., Colomb, M.G., 1993. Mol Immunol 30(2), 129-136.

Williams, C., Addona, T.A., 2000. Trends Biotechnol 18(2), 45-48.

Yu, X., Schneiderhan-Marra, N., Joos, T.O., Clin Chem 56(3), 376-387.

Zhang, Y., Xu, M., Wang, Y., Toledo, F., Zhou, F., 2007. Sens Actuators B Chem 123(2), 784792. 


\section{SUPPLEMENTARY DATA}

Table 1: Sequences of peptides used in this study

\begin{tabular}{|c|c|c|}
\hline Origin & Peptide & Sequence \\
\hline \multirow{5}{*}{$\mathrm{HCV}$} & $\mathrm{C} 2$ & KTKRNTNRRPQDVKFPGGGQ \\
\hline & $\mathrm{E} 2 / 3$ & VVVGTTDRFGVPTYSWG E \\
\hline & $\mathrm{NS} 2 / 1$ & HLQVWIPPLNVRGGRDAIILL \\
\hline & NS4/7 & FASRGNHVSPTHYVPESDAAAR \\
\hline & $\mathrm{NS} 5 / 2$ & AMPIWARPDYNPPLLES WKDPDYVPP \\
\hline \multirow{5}{*}{ HDV } & HDV1-1 & MSRSESRKNRGGREEILE \\
\hline & HDV1-65 & GEGAPPAKRARTDQME \\
\hline & HDV1-155 & LEGGSRGAPGGGFVPNLQ \\
\hline & HDV1-174 & VPESPFSRTGEGLDIRGNQGFP \\
\hline & HDV1-189 & RGNQGFPWDILFPADPPFSPQSC \\
\hline TETANUS TOXIN & $\mathrm{P} 12$ & ELIHVLHGLYGMQVSS \\
\hline Ovalbumin & Ova 74 & GTSVNVHSSLRDILNQITKPND \\
\hline
\end{tabular}

